\title{
THE RADIATION OF HEAT FROM THE HUMAN BODY
}

\author{
III. The Human Skin as a Black-Body Radiator
}

By JAMES D. HARDY

(From The Russell Sage Institute of Pathology, in Affiliation with the New York Hospital, New York City)

(Received for publication February 24, 1934)

According to the law of Kirchhoff the ratio of the radiating power to the absorbing power is the same for all bodies at the same temperature, and therefore a body which absorbs perfectly must radiate perfectly. For that reason a perfect radiator is often referred to as a perfect black-body. All physical bodies radiate somewhat less than a perfect black-body. Surfaces such as polished metal radiate practically nothing whereas other surfaces such as black paint pigment radiate within a few per cent of the theoretical black-body. The human skin has its place among other radiators as regard its emissive power and upon the value of this quantity depends the whole technique of skin temperature measurements by means of radiometric instruments. This factor is of importance in the study of human radiation in general and, incidentally, in the study of ventilation. The human skin has been assumed in the past to radiate as a perfect black-body and the experiments of Cobet and Bramigk (1) confirm this assumption. Realizing the importance of this factor in the measurements of skin temperature when using a radiometer several experiments were performed with an idea of making a quantitative measurement of the emissive power of the skin. These experiments are described below and they do little more than confirm the observations of Cobet and Bramigk.

That the human skin is not truly black, whether white or negro. is obvious and the measurements of Martin (2) show quite conclusively that the reflecting power of even the blackest skin is considerably above zero. The question may then arise as to how the white skin can radiate so perfectly when it is obviously not black. A consideration of Figure 1 will make this clear. Here are plotted the emission curves of the sun (not to scale), a red-hot stove, and the human skin (to scale), assuming the emissivity of the skin to be 100 per cent. The electromagnetic spectrum is plotted somewhat schematically to include all the known radiations, and is to scale only for the visible and near infra-red regions. Due to atmospheric absorption none of the radiation from the sun of wave length longer than $3 \mathrm{mu}$ reaches the earth's surface. On the other hand the human body has no appreciable radiation of wave lengths shorter than $4 \mathrm{mu}$. Thus the 


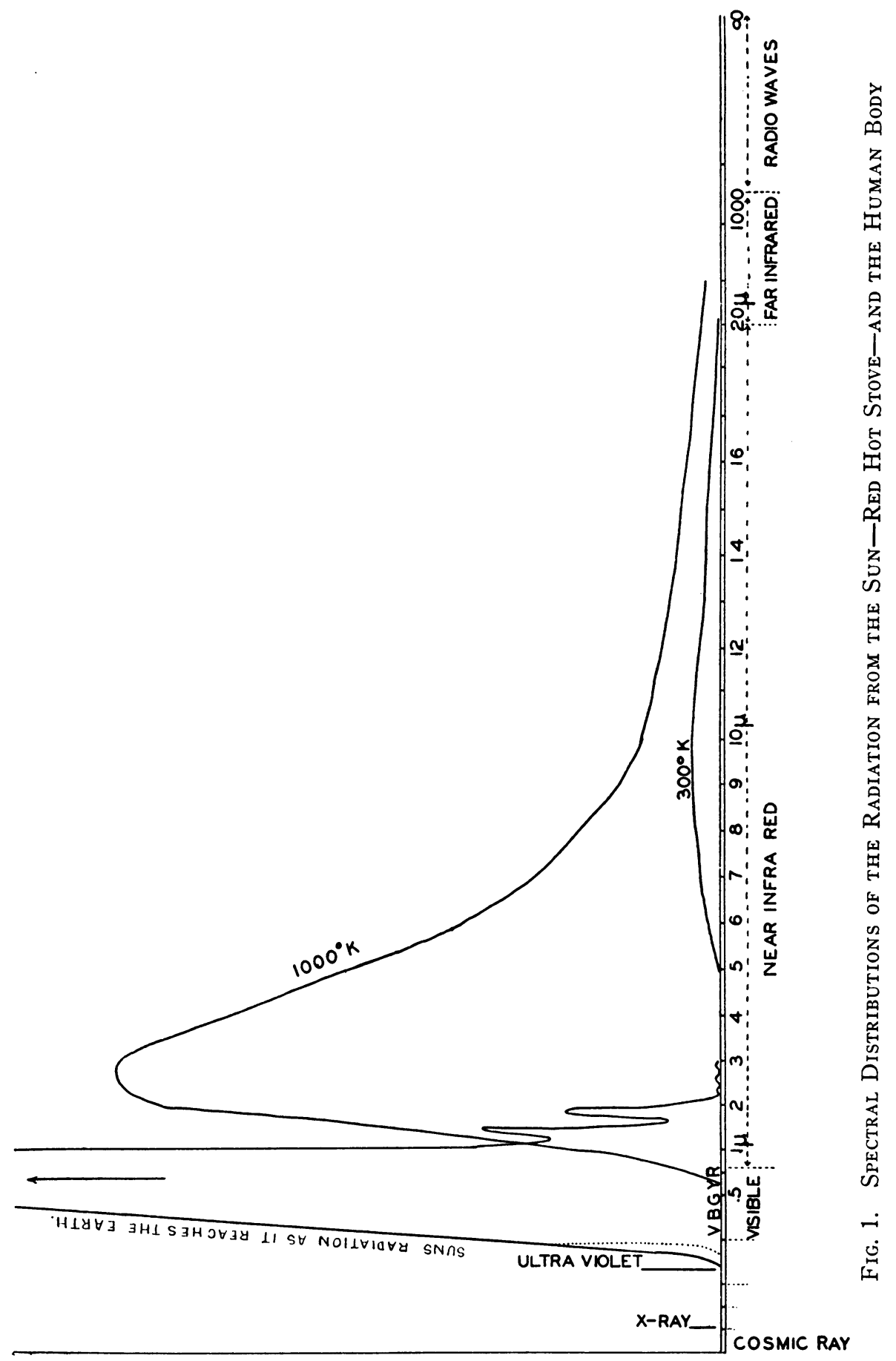


ability of the skin to reflect light of short wave lengths does not preclude the possibility of its absorbing and therefore radiating almost perfectly the longer wave lengths. Therefore the findings of Martin and of Cobet and Bramigk are not in contradiction to Kirchhoff's law. As shown above the regions of body emission and solar reflection do not even overlap. A consideration of the hypothetical emission curve for the skin shows that the visible color of the surface is of no importance in so far as the radiating power of the skin is concerned. To test this assumption a more or less qualitative experiment was performed as follows:

A white subject, parts of whose back had been coated with an absorbing black paint, was measured several times and comparisons were made between the radiation values of the blackened and unblackened surfaces. No significant difference could be detected between the two although the unblackened surfaces radiated slightly more than the blackened surfaces.

In Figure 2 is shown the emission curve for a perfect black body at a temperature of $32^{\circ} \mathrm{C}$. or $305^{\circ} \mathrm{K}$ radiating to surroundings at $22^{\circ} \mathrm{C}$. or $295^{\circ}$ absolute, drawn on a larger scale than in Figure 1. Starting with this curve it is possible to make some investigations as to the closeness with which the emission curve of the skin follows the theoretical one for a blackbody. In order to test this several crystals whose transmission curves are well known were chosen and the total amount of energy transmitted through the crystal compared with the amount absorbed. The materials chosen were glass, crystal quartz, clear $\mathrm{KCl}$, and $\mathrm{NaCl}$. The transmission curves of these materials are shown in the same figure after having been corrected for the thicknesses of crystal used in this experiment. The glass was $1 \mathrm{~mm}$. thick, the quartz $1 \mathrm{~mm}$. thick, the $\mathrm{NaCl} 4 \mathrm{~mm}$. thick and the $\mathrm{KCl} 2.5 \mathrm{~mm}$. thick. Thus by multiplying the emission curve by the transmission curves and using graphic integration the amounts absorbed can be determined. This was done and the results compared with the experimental values obtained for the skin and an experimental black-body. The comparison is set forth in Table I.

TABLE I

Comparison of radiation from black-body and from skin

\begin{tabular}{|c|c|c|c|}
\hline \multirow{2}{*}{ Substance } & \multicolumn{3}{|c|}{ Per cent of incident light transmitted } \\
\hline & Calculated & $\begin{array}{l}\text { Experimental black-body } \\
\text { (cone of Leslie Cube) }\end{array}$ & Skin \\
\hline 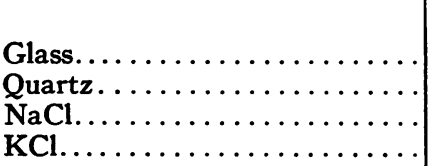 & $\begin{array}{c}\text { per cent } \\
0 \\
0 \\
78 \\
87\end{array}$ & $\begin{array}{c}\text { per cent } \\
0 \\
0 \\
78 \\
88\end{array}$ & $\begin{array}{c}\text { per cent } \\
0 \\
0 \\
78 \\
87\end{array}$ \\
\hline
\end{tabular}

This experiment is not particularly sensitive and is of more value in locating the position of the skin radiation in the spectrum than it is as a 
quantitative test of skin blackness. From it the following conclusions may be drawn: (1) The emission curve of the skin must have approximately the same form as that of a black-body with no large regions of selective absorption or emission: (2) Radiation from the ordinarily moist skin is not greatly affected by the absorption by water vapor or $\mathrm{CO}_{2}$ in the layer of air immediately surrounding the skin.

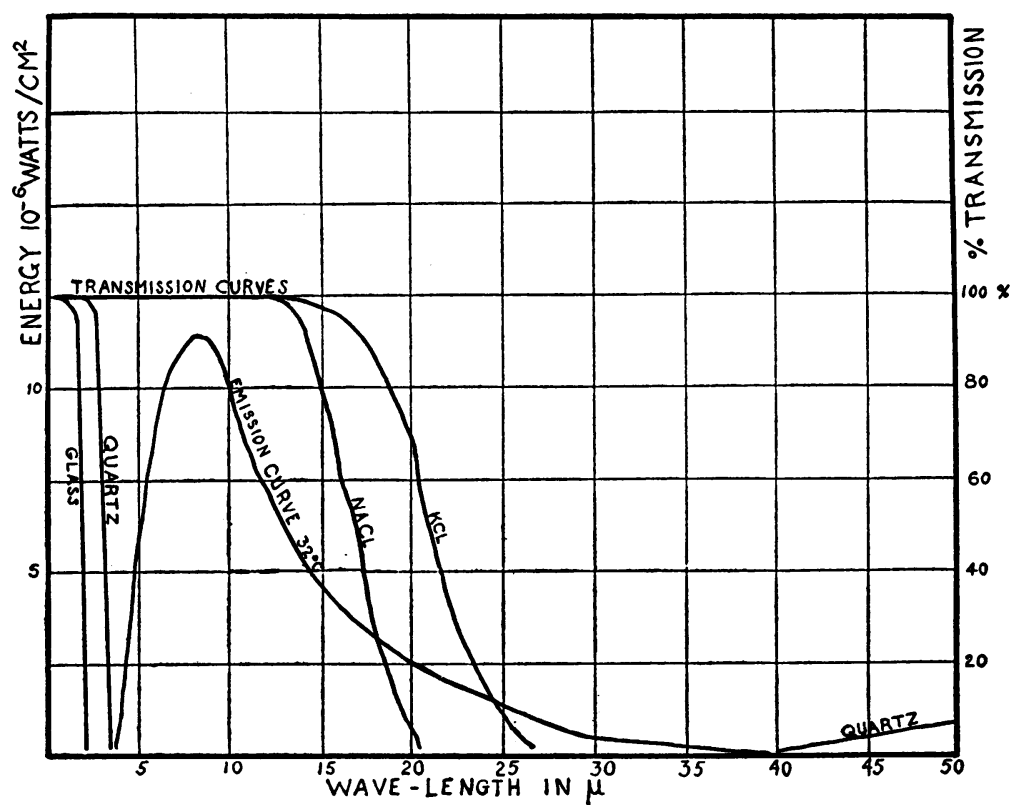

Fig. 2. Crystal-Filter Test of the Radiation from the Human Body

Another, and much more sensitive method for measuring the radiating power of the skin, is that of comparing the radiation of the skin with that of a black-body emitter at the same temperature. In order to test the sensitivity of the method, experiments were performed on various surfaces of known temperature in the following manner.

The Leslie Cube, described in Paper I of this series (3), was arranged so that one surface of the cube contained the cone, or standard black-body emitter; into another side was drilled a hole over which was pasted a thin rubber diaphragm; a third side was painted black with a carbon black; and the fourth side was allowed to retain its usual dull copper finish. The water in the cube was warmed to about skin temperature, $35.8^{\circ} \mathrm{C}$., and the radiation from all four surfaces was measured with a radiometer. Table II gives the comparative data for the experiment.

The sensitivity of the method is evident. The accuracy of the radiometer is \pm 0.1 calorie. It is therefore sensitive to at least a 1 per cent change in the radiating character of the surface. The last column shows the black-body temperature of the surface whose actual temperature is 
given in the first column, thus it is possible that a body might be so highly reflecting as to lose nothing by radiation regardless of its temperature. One of the important properties of clothing brought out by such an experiment is that of changing the radiating surface which man presents to his usually cooler surroundings.

TABLE II

Influence of character of surface on radiation

\begin{tabular}{|c|c|c|c|c|c|}
\hline Surface & $\begin{array}{c}\text { Cube } \\
\text { temperature }\end{array}$ & $\begin{array}{c}\text { R.T.B. } \\
\text { temperature }\end{array}$ & \multicolumn{2}{|c|}{ Radiation } & $\begin{array}{l}\text { Black-body } \\
\text { temperature }\end{array}$ \\
\hline $\begin{array}{l}\text { Cone ........... } \\
\text { Rubber......... } \\
\text { Blackened...... } \\
\text { Copper........ }\end{array}$ & $\begin{array}{l}{ }^{\circ} C . \\
35.8 \\
35.8 \\
35.8 \\
35.8\end{array}$ & $\begin{array}{l}\circ C . \\
25.6 \\
25.6 \\
25.6 \\
25.6\end{array}$ & $\begin{array}{c}\mathrm{cal} / \mathrm{sec} / \mathrm{cm} .^{2} \\
15.6 \\
15.3 \\
14.4 \\
1.4\end{array}$ & $\begin{array}{c}\text { per cent } \\
100 \\
98 \\
93 \\
10\end{array}$ & $\begin{array}{l}{ }^{\circ} C . \\
35.8 \\
35.6 \\
35.0 \\
26.5\end{array}$ \\
\hline
\end{tabular}

The next matter is that of actually measuring the temperature of the skin by a method independent of the radiometer so that the skin temperature can be compared with the black-body temperature, as measured by the radiometer. This was attempted in two ways.

The errors induced in the measurements of skin temperature when using the usual methods have been described (4), and the largest of these was the calibration error. In order to avoid this error the room temperature was raised until it approximated that of the skin. Under these conditions the skin temperature was measured with Benedict's element.

At this temperature the skin and all the apparatus were in approximate equilibrium and the maximum reading of the thermocouple thermometer was $0.7^{\circ} \mathrm{C}$.

The Stefan-Boltzmann Law,

$$
S=E E^{\prime} S_{0}\left(T^{4}-T_{0}^{4}\right),
$$

relates the radiating power of the surface to its temperature. In this equation

$S=$ number of calories radiated by the surface per second per $\overline{\mathrm{cm}}^{2}$ is measured with the radiometer,

$E=$ absorbing power of radiometer and does not enter the calculations (see Paper I (3)),

$E^{\prime}=$ the absorbing (emitting) power of the skin,

$T=$ absolute temperature of the skin measured by the Benedict thermocouple,

$T_{0}=$ absolute temperature of the R.T.B.

Now, if $T$, as calculated on the basis of $E^{\prime}=1$ (known as the equivalent black-body temperature), should equal $T$ as measured by the Benedict thermocouple, $E^{\prime}$ would necessarily be near unity. The accuracy of the experiment is limited by the precision with which the thermocouple thermometer will measure the skin temperature. 
The readings were made on a white subject who did not sweat profusely at this temperature, and the usual complications met with in the use of the thermocouple thermometers seemed to be overcome under these special circumstances. The skin temperature was measured in several points and compared with that of the radiometer. The radiometer gave as an average of ten readings a skin black-body temperature of $36.1^{\circ} \mathrm{C}$. and Benedict's element an actual $36.1^{\circ} \mathrm{C}$. The room temperature was $35.8^{\circ} \mathrm{C}$.

Another method for measuring the skin temperature was that which has been used by Cobet and Bramigk. A mercury thermometer is used to measure the temperature of the axilla. As soon as the thermometer has reached equilibrium the arm is moved and the temperature of the skin surface is measured as rapidly as possible with a radiometer. This experiment was repeated with the result that the mercury thermometer showed an average axilla temperature of $35.8^{\circ} \mathrm{C}$. and the radiometer a skin temperature of $35.8^{\circ} \mathrm{C}$. Thus this method, as sensitive as it is, does not give a value for the emissivity of the skin which is appreciably less than unity.

The whole of the evidence concerning this characteristic of the human skin points to the fact that the skin is as near a black-body as can be detected by experiment. This applies to the white skin as well as to the black and the validity of the radiometric method for skin temperature measurement is sustained on this score.

\section{SUMMARY AND CONCLUSIONS}

Additional evidence has been collected which supports the conclusion of Cobet and Bramigk concerning the emissivity of the skin for infra-red light. The value of the emissivity is put at 100 per cent with a possible error of 1 per cent.

Tests of the emission curve of the human skin show: (1) that it radiates like black-body irrespective of its visible color; (2) that the energy distribution in the spectrum is similar to that of an artificial black-body radiator; (3) that the presence of water vapor and $\mathrm{CO}_{2}$ in the layers of air next to the skin do not appreciably affect the radiation from the surface.

The validity of skin temperature measurements by means of a radiometer is upheld as regards the emissivity of the skin.

\section{BIBLIOGRAPHY}

1. Cobet, R., and Bramigk, F., Über Messung der Wärmestrahlung der menschlichen Haut und ihre klinische Bedeutung. Deutsches Arch. f. klin. Med., 1924, 144, 45.

2. Martin, C. J., Thermal adjustment of man and animals to external conditions. Lancet, 1930, 2, 561, 617, 673.

3. Hardy, J. D., The radiation of heat from the human body. I. An instrument for measuring the radiation and surface temperature of the skin. J. Clin. Invest., 1934, 13, 593.

4. Hardy, J. D., The radiation of heat from the human body. II. The radiation of heat from the human body. II. A comparison of some methods of measurement. J. Clin. Invest., 1934, 13, 605. 